\title{
Comparative analysis of the expected demands for nursing care services among older people from urban, rural, and institutional environments
}

This article was published in the following Dove Press journal:

Clinical Interventions in Aging

2 February 2015

Number of times this article has been viewed

\section{Ewa Borowiak ${ }^{1,2, *}$ \\ Joanna Kostka ${ }^{3, *}$ \\ Tomasz Kostka!}

'Department of Geriatrics, Medical University of Lodz, Poland; ${ }^{2}$ Institute of Nursing, Medical University of Lodz, Poland; ${ }^{3}$ Department of Physical Medicine, Medical University of Lodz, Poland

*These authors contributed equally to this work
Correspondence: Tomasz Kostka

Department of Geriatrics, Healthy Ageing Research Centre (HARC), Medical

University of Lodz, PI Hallera I,

90-647 Lodz, Poland

Tel +48426393215

Fax +48426393218

Email tomasz.kostka@umed.lodz.pl
Background: Demand for nursing and social services may vary depending on the socio-demographic variables, health status, receipt of formal and informal care provided, and place of residence.

Objectives: To conduct a comparative analysis of the expectations of older people from urban, rural, and institutional environments concerning nursing care with respect to the care provided and elements of a comprehensive geriatric assessment.

Material and methods: The study comprised 2,627 individuals above the age of 65 years living in urban $(\mathrm{n}=935)$ and rural $(\mathrm{n}=812)$ areas as well as nursing homes $(\mathrm{n}=880)$.

Results: Family care was most often expected both in urban (56.6\%) and rural (54.7\%) environments, followed by care provided simultaneously by a family and nurse (urban $-18.8 \%$; rural $-26.1 \%$ ) and realized only by a nurse (urban $-24.6 \%$; rural $-19.2 \%$ ). Not surprisingly, nursing home residents most commonly expected nursing care $(57.5 \%)$ but $33.1 \%$ preferred care provided by family or friends and neighbors. In the whole cohort of people living in the home environment $(n=1,718)$, those living with family demonstrated willingness to use primarily care implemented by the family $(62.0 \%)$, while respondents living alone more often expected nursing services $(30.3 \%)$. In the logistic regression model, among the respondents living in the city, only the form of care already received determined the expectations for nursing care. Among the respondents living in the county, the presence of musculoskeletal disorders, better nutritional status, and current care provided by family decreased expectations for nursing care. Higher cognitive functioning, symptoms of depression, and living alone increased the willingness to obtain nursing care.

Conclusion: Older inhabitants of urban areas, rural areas, and those residing in institutions have different expectations for individual nursing care. Nearly $45 \%$ of seniors living in the community expect to obtain nursing care, while only $1.6 \%$ do not expect any social or nursing help. While the expectations for the provision of nursing care are significantly increased by living alone, they are decreased by having access to care provided by family. Support for families to take care of elderly relatives would appear to be essential for an effective nursing and social care system.

Keywords: aging, place of residence, comorbidities, comprehensive geriatric assessment, nursing services

\section{Background}

Aging is perceived as one of the major challenges that Europe will face in the coming years. ${ }^{1,2}$ It is expected that in 2060 almost every third inhabitant of the European Union will be 65 years or older. ${ }^{3}$ The process of demographic aging is also very pronounced in Poland and other Central-European countries where the elderly constitute the fastest 
growing segment of the population. ${ }^{4}$ According to Eurostat data, people aged 65 years and more will constitute nearly $25 \%$ of Polish society in 2020 , while old age dependency ratio (65 or over/15-64 years old) will amount to $36 \%{ }^{5}$ Extending life expectancy is undoubtedly a significant achievement for humanity, but an increasing older population represents a significant challenge for the economies, health systems, and social services of individual countries. An aging population increases the demand for diverse and specific medical services, in response to the declining level of mobility and mental functioning, deteriorating level of proficiency in performing activities of daily living (ADL), and increased negative perception of selfhealth that occurs with advancing age..$^{2,46,7}$ The simultaneous occurrence of many diseases and dysfunctions typical of old age is becoming one of the leading problems faced by community health and social care. ${ }^{8}$ Home-based, nurse-led health care may offer clinical benefits across a number of important health issues. ${ }^{9}$ In order to adapt to the medical and nursing care needs of an aging population, current analyses are required concerning changes in the health and social care systems. ${ }^{10-12}$

Health problems and the level of care obtained by elderly people, together with the demand for nursing and social services, may vary depending on socio-demographic variables, health status, receipt of formal and informal care provided, and place of residence. ${ }^{13,14}$ In Poland, the nurse cares for insured persons over 65 years of age who are declared to her/ him, based on a referral given by a family physician or the patient's own wishes regarding nursing care. Social assistants are also available for patients not able to perform ADL. In our recent report we have shown important differences in the use of home nursing and family care between communitydwelling older people from urban and rural environments. ${ }^{15}$ The aim of the present work was to assess the expectations of seniors regarding the provision of nursing care, and to conduct a comparative analysis of the expectations of older people from urban, rural, and institutional environments concerning nursing care with regard to the care provided and elements of a comprehensive geriatric assessment.

\section{Materials and methods Respondents}

The cross-sectional random survey was carried out in central Poland within the area of the city of Łódź and the neighboring rural county of Sieradz. Data were consecutively collected during several research and educational projects (see Acknowledgments section) coordinated by the Department of Geriatrics and Healthy Ageing Research Centre of the Medical University of Lodz in the period 2006-2012.
The respondents were community-dwelling individuals aged over 65 , living either in urban or in rural areas, and older subjects living in institutions, with efficient verbal communication, and consent given for the participation. The recruitment methodology in community-dwelling elders has been previously described in detail. ${ }^{15}$ In brief, participants were randomly chosen from the databases of two urban and three rural family physician clinics. In total, 935 people from the urban environment and 812 respondents from the rural area fulfilled the recruitment criteria and agreed to participate in the study. The institutionalized subjects were residents of seven nursing homes, together comprising 1,514 inhabitants aged $\geq 65$ years. In nursing homes, 880 older subjects fulfilled the recruitment criteria and agreed to participate in the study. The study was approved by the Ethics Committee of the Medical University of Lodz and written informed consent was obtained from all subjects.

\section{Data collection}

A multi-dimensional face-to-face assessment was performed with each subject using a multiple section questionnaire as described previously. ${ }^{15}$ In brief, the respondent could choose one or more of three options to describe their residential status: alone, with husband/wife/partner or with other family. Subjects who lived both with husband/wife/partner and with other family were coded in multivariate analyses as living with family. For the next question, the community-dwelling respondent would choose one or more of another three options for stating who looked after them: nobody, family/ friends (husband/wife, other family, friends/neighbors) or a family nurse practitioner. Subjects were coded as having family care (yes versus [vs] no) in multivariate analyses.

In the section of the questionnaire on expectations concerning nursing care, the respondent could choose one or more of the following answers indicating preferred care: family, friends/neighbors, a nurse (family nurse practitioner home visits, visits at nurse's office [out-patient clinic], mobile phone contact with the nurse, nursing care at hospital, stay in a nursing home), a social assistant or nobody. Due to the small number of respondents who indicated the lack of expectations for the provision of care by anyone (urban -25 , rural -4 , and institution -12 subjects), those subjects were excluded from further analyses.

A multi-dimensional assessment was completed with the assessment of health status and using the ADL, ${ }^{16}$ the instrumental activities of daily living (IADL), ${ }^{17}$ the mini nutritional assessment (MNA), ${ }^{18}$ the mini-mental state examination (MMSE), ${ }^{19}$ and 15-item geriatric depression scale (GDS) ${ }^{20}$ instruments. ${ }^{15}$ 


\section{Statistical analyses}

The data were verified for normality of distribution and equality of variances. The one way analysis of variance (ANOVA) with Tukey's post hoc testing, Kruskal-Wallis test, and chi-square test ( $3 \times 2$ and $2 \times 2$ with Yates' correction) were used to compare the groups. Pearson product moment and Spearman correlation coefficients were calculated for associations between numerous variables. Those variables statistically significant $(P$-value $<0.05)$ in the bivariate analyses were entered into a multiple logistic regression model adjusted for age and sex to select variables that independently predict expectations for nursing care (yes vs no). Expectation for care provided by both a family and a nurse was coded as "yes". Odds ratios and confidence intervals with $95 \%$ confidence limits were calculated. Results are presented as mean \pm standard deviation. The limit of statistical significance was set at $P=0.05$ for all analyses.

\section{Results}

\section{Characteristics of respondents}

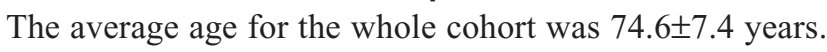
Residents of nursing homes were the oldest, and respondents from the city were the youngest (Table 1). The majority of the cohort were female (68.9\%). The largest proportion of men were found in rural areas, the smallest in nursing homes.

Arterial hypertension prevailed among the diseases diagnosed in the patients (59.7\% of the whole cohort), followed by musculoskeletal disorders (41.9\%). The third most common diagnosis was coronary heart disease $(35.8 \%)$, followed by chronic heart failure (33.8\%) and diabetes (21\%). City and institution dwellers were found to experience ischemic heart disease, musculoskeletal disorders, and gastrointestinal disorders more often than those living in rural areas, and seniors in rural areas were more commonly diagnosed with diabetes than those in the other two groups. Respiratory disorders were noted in nursing home residents and dwellers of rural areas more often than respondents from urban areas. The prevalence of previous stroke, ocular disorders, and osteoporosis was highest in institution residents. The number of medications taken was higher in seniors staying in institutional accommodation compared to community-dwelling elders. Nutrition status (body mass index and MNA) and physical and cognitive functioning indices were generally better in urban than rural seniors and clearly worse in institutionalized elderly (Table 1).

Table I Characteristics of the respondents $(n=2,627)$

\begin{tabular}{|c|c|c|c|c|}
\hline & $\begin{array}{l}\text { Urban environment } \\
(n=935)\end{array}$ & $\begin{array}{l}\text { Rural environment } \\
(n=8 \mid 2)\end{array}$ & $\begin{array}{l}\text { Institutionalized } \\
(\mathrm{n}=\mathbf{8 8 0})\end{array}$ & $\begin{array}{l}\text { Statistical } \\
\text { significance }\end{array}$ \\
\hline Age (years) & $71.7(5.3)$ & $73.0(6.6)^{*}$ & $79.0(7.9)^{*, \dagger}$ & $F=302.0 ; P<0.001$ \\
\hline Men, n (\%) & $292(3 \mid .2)$ & $322(39.7)^{*}$ & $204(23.2)^{*, \dagger}$ & $\chi^{2}=53.5 ; P<0.00 I$ \\
\hline Education (years) & $10.7(3.5)$ & $7.4(2.7)^{*}$ & $8.1(3.3)^{* . \dagger}$ & $F=252.9 ; P<0.00 I$ \\
\hline Smokers, n (\%) & $103(11.0)$ & I8I (22.3)* & $133(15.1)^{*, \dagger}$ & $\chi^{2}=41.9 ; P<0.001$ \\
\hline Ischemic heart disease, n (\%) & $359(38.4)$ & $252(31.0)^{*}$ & $330(37.5)^{\dagger}$ & $\chi^{2}=11.87 ; P=0.003$ \\
\hline Hypertension, n (\%) & $547(58.5)$ & $484(59.6)$ & $537(6 I .0)$ & NS \\
\hline Chronic heart failure, $\mathrm{n}(\%)$ & $282(30.2)$ & $253(3 \mid .2)$ & $354(40.2)^{*, \dagger}$ & $\chi^{2}=24.3 ; P<0.001$ \\
\hline Post-myocardial infarction, n (\%) & $100(10.7)$ & $83(10.2)$ & $99(11.3)$ & NS \\
\hline Post-stroke, n (\%) & $56(6.0)$ & $73(9.0)^{*}$ & $174(19.8)^{*, \dagger}$ & $\chi^{2}=91.7 ; P<0.001$ \\
\hline Musculoskeletal disorders, n (\%) & $4 \mid 8(44.7)$ & $260(32.0)^{*}$ & $423(48.1)^{\dagger}$ & $\chi^{2}=49.3 ; P<0.001$ \\
\hline Respiratory disorders, n (\%) & $59(6.3)$ & $97(12.0)^{*}$ & $122(13.9)^{*}$ & $\chi^{2}=29.6 ; P<0.00 I$ \\
\hline Gastrointestinal disorders, n (\%) & $135(14.4)$ & $38(4.7)^{*}$ & $118(13.4)^{\dagger}$ & $\chi^{2}=49.3 ; P<0.001$ \\
\hline Diabetes, n (\%) & $187(20.0)$ & $196(24.2)^{*}$ & $168(19.1)^{\dagger}$ & $\chi^{2}=7.4 ; P=0.02$ \\
\hline Ocular disorders (glaucoma, cataract), n (\%) & $132(14.1)$ & $73(9.0)^{*}$ & $191(21.7)^{*, \dagger}$ & $\chi^{2}=54.3 ; P<0.00 I$ \\
\hline Osteoporosis, n (\%) & $122(13.1)$ & $43(5.3)^{*}$ & I84 (20.9)*, & $\chi^{2}=89.4 ; P<0.001$ \\
\hline Medications (number) & $4.5(3.2)$ & $4.7(2.9)$ & $5.8(3.4)^{*, \dagger}$ & $F=40.8 ; P<0.00 I$ \\
\hline Body mass index $\left(\mathrm{kg}^{*} \mathrm{~m}^{-2}\right)$ & $27.6(4.6)$ & $27.1(5.3)$ & $25.8(4.9)^{*, \dagger}$ & $F=30.7 ; P<0.00 I$ \\
\hline MNA & $24.9(3.2)$ & $23.1(3.9)^{*}$ & $21.3(4.8)^{*, t}$ & $F=|77.8 ; P<0.00|$ \\
\hline GDS & $4.9(3.4)$ & $6.9(3.5)^{*}$ & $6.8(4.0)^{*}$ & $F=86.5 ; P<0.001$ \\
\hline MMSE & $27.5(3.3)$ & $26.1(5.4)^{*}$ & $21.9(6.2)^{*, \dagger}$ & $F=288.3 ; P<0.00 I$ \\
\hline ADL & $5.7(0.7)$ & $5.3(1.2)^{*}$ & $4.4(2.0)^{*, \dagger}$ & $F=219.2 ; P<0.001$ \\
\hline IADL & $7.3(1.7)$ & $4.9(3.0)^{*}$ & $3.6(3.0)^{* t}$ & $F=468.1 ; P<0.00 I$ \\
\hline
\end{tabular}

Notes: *Significantly different $(P<0.05)$ from urban environment; †'significantly different $(P<0.05)$ from rural environment. Data presented as mean $($ standard deviation) and numbers (percentages).

Abbreviations: NS, not significant; MNA, mini nutritional assessment; ADL, activities of daily living; IADL, instrumental activities of daily living; GDS, geriatric depression scale; MMSE, mini-mental state examination. 
Table 2 Expectations for care and nursing services in elderly people from urban, rural, and institutional environments ( $\mathrm{n}=2,586$ )

\begin{tabular}{lllll}
\hline & $\begin{array}{l}\text { Urban environment } \\
(\mathbf{n = 9 1 0 )}\end{array}$ & $\begin{array}{l}\text { Rural environment } \\
(\mathbf{n = 8 0 8 )}\end{array}$ & $\begin{array}{l}\text { Institutionalized } \\
(\mathbf{n}=\mathbf{8 6 8})\end{array}$ & $\begin{array}{l}\text { Statistical } \\
\text { significance }\end{array}$ \\
\hline Respondent would like to use care of (\%) & & & & \\
$\quad$ Family/friends/neighbors & 56.6 & 54.7 & $33.1^{*, \dagger}$ & $\chi^{2}=343.4 ; P<0.001$ \\
$\quad \begin{array}{l}\text { Family nurse practitioner } \\
\text { Family/friends/neighbors and family nurse practitioner }\end{array}$ & 24.6 & 18.8 & $57.5^{*+,}$ & \\
\hline
\end{tabular}

Notes: *Significantly different $(P<0.05)$ from urban environment; ’ significantly different $(P<0.05)$ from rural environment.

\section{Family situation and forms of care among respondents living in urban and rural environments}

The city dwellers more frequently lived with their spouses ( $35.2 \%$ vs $17.6 \%$ ) or alone (32.8\% vs $17.9 \%$ ) than their rural peers. The rural dwellers most frequently lived with their families (64.5\% vs $32.0 \%)$. Both in urban and rural areas, the persons living alone or with their families were older than those living with their spouses. In both environments, women lived alone more often than men.

Nursing care services were provided to 38 (4.1\%) older people in the urban environment and $53(6.5 \%)$ in rural areas. A significant difference was demonstrated between the place of residence and the form of care. Urban residents (44.7\%) were more likely to report a lack of care from other persons than the group of respondents from rural areas (10.7\%). The rural residents $(82.8 \%)$ were more likely than their urban peers $(51.2 \%)$ to nominate their family members as care providers.

\section{Respondents' expectations for the provision of nursing care}

Twenty-five urban residents, four from rural areas and eleven from institutions did not declare any wish to use any form of care. Subjects with advanced age more often expected to receive nursing care $(F=35.8 ; P<0.001)$. Sex had no relationship to expectations for nursing care.

The expectations for care and nursing services in elderly people from urban, rural, and institutional environments are shown in Table 2. Not surprisingly, nursing home residents were found to be the most likely of the three groups to expect nursing care (57.5\% of nursing home residents). In contrast, the family was the most commonly expected source of care in both urban (56.6\%) and rural (54.7\%) environments. A desire to take advantage of care provided simultaneously by both nurse and family was a little less common (urban - 18.8\%; rural $-26.1 \%$ ) as well as care from a nurse (urban $-24.6 \%$; rural $-19.2 \%$ ). Inhabitants of rural areas expected simultaneous care provided by family and a nurse more often than urban dwellers (Table 2).

The expected forms of care and nursing services with respect to the environment of residence, ie, urban or rural, are presented in Table 3, with more than one answer being possible from each respondent. Of the whole communitydwelling population, the expected forms of care provided by nurses were direct contact at home $(15.5 \%)$, telephone contact (5.8\%), and direct contact at an outpatient clinic (1.7\%), with $19 \%$ expressing a willingness to use nursing care offered in hospital and $3.9 \%$ care in a nursing home. Care provided by social caregivers was expected by $2 \%$ of

Table 3 Expected forms of care and nursing services (more than one answer possible) depending on the environment of residence (urban or rural) ( $n=I, 7 \mid 8)$

\begin{tabular}{|c|c|c|c|}
\hline Preferred form of nursing care (\%) & $\begin{array}{l}\text { Urban environment } \\
(n=9 \mid 0)\end{array}$ & $\begin{array}{l}\text { Rural environment } \\
(n=808)\end{array}$ & $\begin{array}{l}\text { Statistical } \\
\text { significance }\end{array}$ \\
\hline Family member (husband/wife/partner, children, grandchildren) & 68.6 & 75.7 & $P=0.001$ \\
\hline Friends/neighbors & 6.3 & 8.0 & NS \\
\hline Care by social assistants of the Polish Red Cross/Polish Social Assistance Committee & 3.5 & 0.4 & NS \\
\hline Nursing care at place of residence & 19.8 & 10.8 & $P<0.001$ \\
\hline Direct contact with a nurse at an out-patient clinic & 2.7 & 0.5 & $P<0.001$ \\
\hline Contact with a nurse by mobile phone & 9.9 & 1.1 & $P<0.001$ \\
\hline Stay in a nursing home & 4.2 & 3.6 & NS \\
\hline Stay in hospital & 5.9 & 33.8 & $P<0.00$ I \\
\hline Other form of care & 4.3 & 0.1 & $P<0.001$ \\
\hline
\end{tabular}

Abbreviation: NS, not significant. 
Table 4 Expectations for care and nursing services depending on the family situation $(n=1,7 \mid 8)$

\begin{tabular}{|c|c|c|c|c|}
\hline & $\begin{array}{l}\text { Living with a spouse/ } \\
\text { partner }(n=466)\end{array}$ & $\begin{array}{l}\text { Living with family } \\
(\mathrm{n}=8 \mid 3)\end{array}$ & $\begin{array}{l}\text { Living alone } \\
(n=439)\end{array}$ & $\begin{array}{l}\text { Statistical } \\
\text { significance }\end{array}$ \\
\hline \multicolumn{5}{|l|}{ Respondent would like to use care of (\%) } \\
\hline Family/friends/neighbors & 55.1 & $62.0 *$ & $47.8^{*, \dagger}$ & $\chi^{2}=37.5 ; P<0.001$ \\
\hline Family nurse practitioner & 22.9 & $16.3 *$ & $30.3^{*, \dagger}$ & \\
\hline Both family/friends/neighbors and family nurse practitioner & 22.0 & 21.7 & 21.9 & \\
\hline
\end{tabular}

Notes: *Significantly different $(P<0.05)$ from respondents living with a spouse/partner; †'significantly different $(P<0.05)$ from respondents living with family.

respondents and help from neighbors by $7.1 \%$ of respondents. Older subjects from the urban environment preferred nursing care at the place of residence, contact with a nurse by mobile phone, and contact with a nurse at an outpatient clinic. Older community-dwelling residents from rural areas would more often rely on family care and, surprisingly often, nursing care in hospital (Table 3).

Of the whole cohort of people living in the home environment ( $\mathrm{n}=1,718), 62.0 \%$ of those living with family demonstrated a willingness to use primarily care implemented by the family. Respondents living alone more often expected nursing services to be provided (30.3\%) (Table 4).

Community-dwelling subjects who had already benefited from nursing care indicated nurses as the most desirable care providers (Table 5). Those community-dwellers without any current care indicated nurses as preferred caregivers more often than elders obtaining care from a spouse, family, a friend or a neighbor (Table 5).

Care from a nurse was more commonly expected by urban respondents with gastrointestinal disorders $\left(\chi^{2}=4.7 ; P=0.03\right)$ and with lower level of cognitive functioning according to MMSE ( $F=7.7 ; P=0.005)$. Respondents living in rural areas demanding nursing care reported higher intensity of smoking ( $\left.\chi^{2}=12.6 ; P<0.001\right)$, lower prevalence of musculoskeletal disorders $\left(\chi^{2}=21.5 ; P<0.001\right)$, worse nutritional status $(F=8.6 ; P=0.003)$, higher level of cognitive functioning according to $\operatorname{MMSE}(F=5.2 ; P=0.023)$, and a greater number of symptoms which may indicate depression according to the 15 -item geriatric depression scale $(F=7.7 ; P=0006)$.

\section{Multiple logistic regression analysis}

The effect of all independent variables statistically significant $(P$-value $<0.05)$ in the bivariate analyses on a dependent variable, ie, expectations for the provision of nursing care (yes vs no), was analyzed simultaneously using a logistic regression model adjusted for age and sex.

Among the respondents living in the city, only form of care already received determined the expectations for nursing care. Subjects whose current care was provided by family had lower expectations for nursing care (Table 6). However, among the rural respondents, the presence of musculoskeletal disorders, better nutritional status, and current care provided by family decreased expectations for nursing care. Higher cognitive functioning, symptoms of depression, and living alone increased willingness to obtain nursing care (Table 7).

Throughout the whole sample, including urban and rural dwellers, the presence of musculoskeletal disorders and better nutritional status decreased the declared willingness to use the care provided by nurses (Table 8). Living alone increased expectations for nursing care, while benefiting from the current care provided by a family decreased them (Table 8).

\section{Discussion}

With advancing age and the increasing occurrence of chronic diseases, dependence on other people in everyday care grows, together with the need to use health care provided both at home and in institutions. ${ }^{21,22}$ The provision of comprehensive community care that would enable the senior to stay at

Table 5 Expectations for care and nursing services depending on the care provided $(n=1,7 \mid 8)$

\begin{tabular}{|c|c|c|c|c|}
\hline & $\begin{array}{l}\text { No caregivers } \\
(n=485)\end{array}$ & $\begin{array}{l}\text { Care is provided } \\
\text { by a spouse/family/ } \\
\text { friend/neighbor } \\
(n=I, \mid 44)\end{array}$ & $\begin{array}{l}\text { Care is provided } \\
\text { by a family nurse } \\
\text { practitioner } \\
(n=89)\end{array}$ & $\begin{array}{l}\text { Statistical } \\
\text { significance }\end{array}$ \\
\hline \multicolumn{5}{|l|}{ Respondent would like to use care of (\%) } \\
\hline Family/friends/neighbors & 51.0 & $61.0 *$ & $12.4^{*, \dagger}$ & $\chi^{2}=98.7 ; P<0.001$ \\
\hline Family nurse practitioner & 28.7 & $17.3 *$ & $47.2^{*, \dagger}$ & \\
\hline Both family/friends/neighbors and family nurse practitioner & 20.3 & 21.7 & $40.4^{*, \dagger}$ & \\
\hline
\end{tabular}

Notes: *Significantly different $(P<0.05)$ from respondents who do not have any care provided; 'significantly different $(P<0.05)$ from respondents who have spouse/family/ friend/neighbor care. 
Table 6 Independent predictors of demand for nursing care by the community-dwelling elderly from urban environment $(n=910)$

\begin{tabular}{ll}
\hline & $\begin{array}{l}\text { Odds ratio for expectations } \\
\text { for nursing care }\end{array}$ \\
\hline $\begin{array}{l}\text { Form of care }- \text { care } \\
\text { provided by family }\end{array}$ & $0.61^{* * *}(0.45-0.8 \mathrm{I})$ \\
\hline
\end{tabular}

Notes: $* * * P<0.001$; adjusted for age and sex. Data presented as odds ratios and $95 \%$ confidence intervals.

home is a significant challenge worldwide. ${ }^{23}$ The problem of insufficient care is experienced by both older people and their relatives. ${ }^{21,24}$ One of the determinants of the benefits to patient health gained from nursing care and the expectations for this type of service may be the place of residence. ${ }^{13}$

More than half of the community-dwelling elderly surveyed in the present study expected care provided by family members or friends and neighbors. It should also be emphasized that more than $40 \%$ of older nursing home residents, despite their circumstances, declared an intention to benefit from care provided by family, friends or neighbors, implying that the most preferable source of care for seniors is the family. The informal care provided by nearest family is known to be fraught with problems: lack of time because of the need to work, other responsibilities, lack of economic support, and above all the scarcity of knowledge in the field of health and care. ${ }^{25-27}$ Nevertheless, living alone was the most powerful predictor of increased demand for nursing care, while support from family was the most significant factor protecting against it. Therefore, it seems that lonely older adults living in large cities where family care is often limited should be the primary target for closer supervision of family nurses and social carers. ${ }^{28}$

The lowest expectations for nursing care were demonstrated by residents of rural areas. A similar observation has been reported in a nationally representative interview from South Korea. ${ }^{29}$ Elderly persons from the rural areas more

Table 7 Independent predictors of demand for nursing care by the community-dwelling elderly from rural environment $(n=808)$

\begin{tabular}{ll}
\hline & $\begin{array}{l}\text { Odds ratios for expectations } \\
\text { for nursing care }\end{array}$ \\
\hline Musculoskeletal disorders & $0.54^{*}(0.39-0.76)$ \\
MNA & $0.94^{* *}(0.90-0.97)$ \\
GDS & $1.06^{*}(1.01-1.11)$ \\
MMSE & $1.05^{* *}(1.02-1.09)$ \\
Family situation - living alone & $2.11^{* * *}(1.34-3.32)$ \\
Form of care - care provided & $0.37^{* * *}(0.23-0.58)$ \\
by family & \\
\hline
\end{tabular}

Notes: $* P<0.05 ; * * P<0.01 ; * * * P<0.001$; adjusted for age and sex. Data presented as odds ratios and $95 \%$ confidence intervals.

Abbreviations: MNA, mini nutritional assessment; GDS, geriatric depression scale; MMSE, mini-mental state examination.
Table 8 Independent predictors of demand for nursing care by the community-dwelling elderly from both urban and rural environments $(n=|, 7| 8)$

\begin{tabular}{ll}
\hline & $\begin{array}{l}\text { Odds ratios for expectations } \\
\text { for nursing care }\end{array}$ \\
\hline Musculoskeletal disorders & $0.7 I^{\text {**** }}(0.58-0.87)$ \\
MNA & $0.94 * * *(0.92-0.97)$ \\
Family situation - living alone & $1.38^{* * *}(1.09-1.75)$ \\
Form of care - care provided & $0.5 I^{* * *}(0.4 I-0.63)$ \\
by family & \\
\hline
\end{tabular}

Notes: $* * * P<0.001$; adjusted for age and sex. Data presented as odds ratios and $95 \%$ confidence intervals.

Abbreviation: MNA, mini nutritional assessment.

often live with family in one household and traditionally, family members and the rural community usually take care of their seniors. Only in circumstances in which the exercise of care by the family is limited can an increased share of formal nursing care be observed. ${ }^{15}$ Surprisingly, nearly $35 \%$ of the rural cohort in the present study noted a willingness to take advantage of nursing care in a hospital. This result is probably caused by the difficulties associated with access to specialized medical services in rural areas.

Age, sex, disability, and co-existing diseases are possible predictors of a willingness to use home care nursing services..$^{29}$ In the present study, sex was not a determinant, while advanced age and physical disability were predictors only in bivariate relationships in the whole studied population and in an institutional environment. In community-dwelling elderly and in any multivariate analyses, age and physical disability measured either according to the ADL or IADL instruments were not determinants of expectations to use home care nursing services. These findings may appear surprising but similar results were obtained by Cho. ${ }^{29}$ These results suggest that physical functional dependency is only one, and probably not the most important, predictor of the needs for home care nursing services. Other factors such as depression and cognitive functioning, concomitant diseases, nutritional status, and access to formal and informal care also need to be taken into account.

The higher demand for nursing care in older subjects with higher depression and cognitive functioning scores demonstrated in rural areas seems worthy of interest. A traditional, multi-generational family model which treats worsening cognitive functioning as a physiological symptom of the aging process or as a problem that should not be publicly considered or even treated are possible explanations for those findings. At the same time, it may indicate insufficient health awareness concerning cognitive functioning and inadequate medical and nursing care in this group of 
seniors. ${ }^{26,27,30}$ Similarly, a rather surprising finding is demonstrated in rural areas' lower demand for nursing care, and hence, higher demand for family care, in elders with musculoskeletal disorders. The greater observed expectation of care from the family by seniors with a degenerative disease of the musculoskeletal system may be explained by the progressive nature of this disease, often causing inability to perform ADL and necessitating the use of continuous care. According to the traditional approach, such care can be provided mainly by family or non-specialized carers such as neighbors or friends. Therefore, it seems that the relatives and other non-specialized caregivers operating in rural areas should be given greater support. ${ }^{25,31,32}$

Many studies highlight the importance of nutritional status of the elderly. There is no doubt that nutritional status may be a major factor in determining the level of physical functional fitness, cognitive functioning, and quality of life. ${ }^{33,34}$ In the current study, poor nutritional status was an independent predictor of demand for professional nursing care, especially in the rural environment. It seems that a systematic assessment of the nutritional status of people over 65 years of age and general education of the public in terms of desired eating behaviors should become routine nursing practice. ${ }^{35}$

Some limitations of the present study should be highlighted. Efficient verbal communication was an inclusion criterion and patients with severe dementia or terminal illness were excluded. Observed associations may be different in other countries and cultures due to differences in sociodemographic status, concomitant diseases, and physical and cognitive functioning. The definition of nursing services may vary between countries with different contribution of other services like case managers or social assistants. The willingness to use nursing care provided at home may differ in different cultures, eg, the majority of older people in North America express such readiness as compared to only half of elders in South Korea. ${ }^{29,36}$ There is also a need in future studies to consider various forms of contact with professional medical personnel. During the occurrence of health problems, both acute and chronic use of modern technologies such as the telephone or the Internet increases the availability of knowledge and reduces feelings of anxiety, loneliness or social isolation, and also reduces the need for medical and nursing care services. ${ }^{37-40}$

\section{Conclusion}

Older inhabitants of urban areas and rural areas, and those residing in institutions have different expectations for indi- vidual social services and nursing care. Nearly $45 \%$ of seniors living in the community expect to obtain nursing care. Only $1.6 \%$ of older community-dwelling people do not expect any social or nursing help. Living alone significantly increases the demand for the provision of nursing care, while having access to care provided by a family decreases expectations for the provision of nursing care. Support for the family to take care of elderly relatives seems essential for the nursing and social care system.

\section{Acknowledgments}

This study was supported by grant no NN404 049633 from the Ministry of Education and Science and the State Committee for Scientific Research, by Polkard Senior Study grant from the Ministry of Health and by grant 503/6-07701/503-01 from the Medical University of Lodz. The authors were partially supported by the Healthy Ageing Research Centre project (REGPOT-2012-2013-1, 7FP).

We appreciate the assistance of Emilia Adamiak, Elżbieta Braksator, Anna Będzichowska, Krystyna Bogus, Wiesława Bogusz, Katarzyna Ciepłoch, Joanna Czarnecka, Barbara Deka, Izabela Kośla, Małgorzata Kusiak, Leena Mary Mascharenhas, Monika Maliszak, Magdalena Ozga, Marta RetlikowskaLipińska, Katarzyna Rosiak, Grażyna Ryszkiewicz, Monika Smolarek, Ewa Trzuskowska, Danuta Wantkiewicz, Danuta Zając and Halina Żarnecka in carrying out the study.

\section{Disclosure}

The authors report no conflicts of interest in this work.

\section{References}

1. World Health Organization. Strategy and action plan for healthy ageing in Europe, 2012-2020. Regional Committee for Europe Sixty-second session. September 10-13; 2012; Malta.

2. Sutcliffe C, Hughes J, Chester H, Xie C, Challis D. Changing patterns of care coordination within old-age services in England. Care Manag J. 2010;11(3):157-165.

3. European Commision. Greying Europe - we need to prepare now 15/05/2012. Available from: http://ec.europa.eu/news/economy/120515 pl.htm. Accessed October 14, 2014.

4. Szukalski P. [Decomposition of changes in life expectancy by age groups, Poland, 1950-2008]. Przegl Epidemiol. 2010;64:425-430. Polish.

5. European Commission. Demography report 2010. Older, more numerous and diverse Europeans. doi:10.2767/79004. Available from: http://epp. eurostat.ec.europa.eu/cache/ITY_OFFPUB/KE-ET-10-001/EN/KE-ET10-001-EN.PDF. Accessed October 14, 2014.

6. Borowiak E, Kostka T. Predictors of quality of life in older people living at home and in institutions. Aging Clin Exp Res. 2004;16(3):212-220.

7. LaPlante MP. The classic measure of disability in activities of daily living is biased by age but an expanded IADL/ADL measure is not. $J$ Gerontol B Psychol Sci Soc Sci. 2010;65(6):720-732.

8. Gulley SP, Rasch EK, Chan L. If we build it, who will come? Workingage adults with chronic health care needs and the medical home. Med Care. 2011;49(2):149-155. 
9. Tappenden P, Campbell F, Rawdin A, Wong R, Kalita N. The clinical effectiveness and cost-effectiveness of home-based, nurse-led health promotion for older people: a systematic review. Health Technol Assess. 2012;16(20): $1-72$.

10. Graves N, Courtney M, Edwards H, Chang A, Parker A, Finlayson K. Cost-effectiveness of an intervention to reduce emergency readmissions to hospital among older patients. PLoS One. 2009; 4(10):e7455.

11. Kim SH. Older people's expectations regarding ageing, health-promoting behaviour and health status. $J$ Adv Nurs. 2009;65(1):84-91.

12. Luck T, Motzek T, Luppa M, et al. Effectiveness of preventive home visits in reducing the risk of falls in old age: a randomized controlled trial. Clin Interv Aging. 2013;8:697-702.

13. Lau R, Morse CA. Health and wellbeing of older people in Anglo-Australian and Italian-Australian communities: a rural-urban comparison. Aust J Rural Health. 2008;16(1):5-11.

14. Imhof L, Naef R, Wallhagen MI, Schwarz J, Mahrer-Imhof R. Effects of an advanced practice nurse in-home health consultation program for community-dwelling persons aged 80 and older. J Am Geriatr Soc. 2012;60(12):2223-2231.

15. Borowiak E, Kostka T. Comparative characteristics of the home care nursing services used by community-dwelling older people from urban and rural environments. $J$ Adv Nurs. 2013;69(6):1259-1268.

16. Katz S, Ford AB, Moskowitz RW, Jackson BA, Jaffe MW. Studies of illness in the aged: The index of ADL, a standardized measure of biological and psychosocial function. JAMA. 1963;185:914-919.

17. Lawton MP, Brody EM. Assessment of older people: selfmaintaining and instrumental activities of daily living. Gerontologist. 1969;9(3):179-186.

18. Guigoz YB, Vellas B, Garry PJ. Mini Nutritional Assessment: a practical assessment tool for grading the nutritional state of elderly patients. Facts and Research in Gerontology. 1994;2:15-59.

19. Folstein MF, Folstein SE, McHugh PR. "Mini-Mental State": a practical method for grading the cognitive state of patients for the clinician. J Psychiatr Res. 1975;12(3):189-198.

20. Yesavage JA, Brink T, Lom O, et al. Development and validation of a geriatric depression screening scale: a preliminary report. $J$ Psychiatr Res. 1983;17(1):37-49.

21. Muszalik M, Dijkstra A, Kędziora-Kornatowska K, ZielińskaWięczkowska H, Kornatowski T, Kotkiewicz A. Independence of elderly patients with arterial hypertension in fulfilling their needs, in the aspect of functional assessment and quality of life (QoL). Arch Gerontol Geriatr. 2011;52(3):e204-e209.

22. León-Muñoz LM, López-García E, Graciani A, Guallar-Castillón P, Banegas JR, Rodríguez-Artalejo F. Functional status and use of health care services: longitudinal study on the older adult population in Spain. Maturitas. 2007;58(4):377-386.

23. Ryan AA, McCann S, McKenna H. Impact of community care in enabling older people with complex needs to remain at home. Int $J$ Older People Nurs. 2009;4(1):22-32.
24. Kim EY, Cho E, June KJ. Factors influencing use of home care and nursing homes. $J A d v$ Nurs. 2006;54(4):511-517.

25. Salin S, Kaunonen M, Astedt-Kurki P. Informal carers of older family members: how they manage and what support they receive from respite care. J Clin Nurs. 2009;18(4):492-501.

26. Dahlrup B, Nordell E, Andrén S, Elmståhl S. Family caregivers' assessment of symptoms in persons with dementia using the GBS-scale: differences in rating after psychosocial intervention - an 18-month follow-up study. Clin Interv Aging. 2011;6:9-18.

27. Werner P, Heinik J, Giveon S, Segel-Karpas D, Kitai E. Help-seeking preferences in the area of mild cognitive impairment: comparing family physicians and the lay public. Clin Interv Aging. 2014;9:613-619.

28. Thumé E, Facchini LA, Wyshak G, Campbell P. The Utilization of Home Care by the Elderly in Brazil's Primary Health Care System. Am J Public Health. 2011;101(5):868-874.

29. Cho SH. Older people's willingness to use home care nursing services. $J$ Adv Nurs. 2005;51(2):166-173.

30. Nikmat AW, Hawthorne G, Al-Mashoor SH. Quality of life in dementia patients: nursing home versus home care. Int Psychogeriatr. 2011; 23(10):1692-1700.

31. Grässel E, Trilling A, Donath C, Luttenberger K. Support groups for dementia caregivers-predictors for utilisation and expected quality from a family caregiver's point of view: a questionnaire survey part I*. $B M C$ Health Serv Res. 2010;10:219.

32. Roe B, Howell F, Riniotis K, Beech R, Crome P, Ong BN. Older people and falls: health status, quality of life, lifestyle, care networks, prevention and views on service use following a recent fall. J Clin Nurs. 2009; 18(16):2261-2272.

33. Khater MS, Abouelezz NF. Nutritional status in older adults with mild cognitive impairment living in elderly homes in Cairo, Egypt. J Nutr Health Aging. 2011;15(2):104-108.

34. Arija V, Martín N, Canela T, et al. Nutrition education intervention for dependent patients: protocol of a randomized controlled trial. $B M C$ Public Health. 2012;12:373.

35. Skates JJ, Anthony PS. Identifying geriatric malnutrition in nursing practice: the Mini Nutritional Assessment $\left(\mathrm{MNA}^{\circledR}\right)$-an evidence-based screening tool. J Gerontol Nurs. 2012;38(3):18-27.

36. Ratner E, Norlander L, McSteen K. Death at Home Following a Targeted Advance-Care Planning Proces at Home: The Kitchen Table Discussion. $J$ Am Geriatr Soc. 2001;49(6):778-781.

37. Margaret $\mathrm{C}$, Glenda $\mathrm{C}$, Fiona $\mathrm{H}$. How to use web-based information to support people with dementia. Nurs Older People. 2012;24(9):14-20.

38. Carr CH, McNeal H, Regalado E, Nelesen RA, Lloyd LS. PAL-MED CONNECT $\left({ }^{\circledR}\right)$ : A Telephone Consultation Hotline for Palliative Medicine Questions. J Palliat Med. 2013;16(3):263-267.

39. Elsom S, Sands N, Roper C, Hoppner C, Gerdtz M. Telephone survey of service-user experiences of a telephone-based mental health triage service. Int J Ment Health Nurs. 2013;22(5):437-443.

40. Benefield LE, Beck C. Reducing the distance in distance-caregiving by technology innovation. Clin Interv Aging. 2007;2(2):267-272.
Clinical Interventions in Aging

\section{Publish your work in this journal}

Clinical Interventions in Aging is an international, peer-reviewed journal focusing on evidence-based reports on the value or lack thereof of treatments intended to prevent or delay the onset of maladaptive correlates of aging in human beings. This journal is indexed on PubMed Central, MedLine,

\section{Dovepress}

CAS, Scopus and the Elsevier Bibliographic databases. The manuscript management system is completely online and includes a very quick and fair peer-review system, which is all easy to use. Visit http://www.dovepress. com/testimonials.php to read real quotes from published authors. 